\title{
Experimental and numerical buckling analysis of delaminated hybrid composite beam structures
}

\author{
M.M. Nasr Esfahani, ${ }^{1,}$, H. Ghasemnejad ${ }^{2, b}$ and P.E. Barrington ${ }^{3, c}$ \\ 1,2,3 Kingston University, Faculty of Engineering, London, SW15 3DW, UK

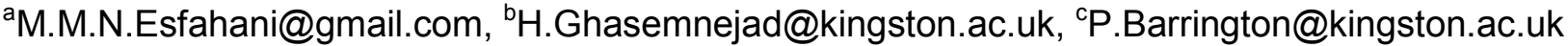

Keywords: Buckling; Delamination; Hybrid; Composite; ANSYS

\begin{abstract}
In this paper the effect of delamination position on the critical buckling load and buckling mode of hybrid composite beams is investigated. Experimental and numerical studies are carried out to determine the buckling load of delaminated composite beams. The laminated composite beams with various laminate designs of $\left[\mathrm{G}_{90}\right]_{6},\left[\mathrm{C}_{90}\right]_{8},\left[\mathrm{C}_{0} / \mathrm{G}_{0}\right]_{4}$ and $\left[\mathrm{C}_{90} / \mathrm{G}_{90}\right]_{4}$ were manufactured and tested to find the critical buckling load. Three different defect positions were placed through the thickness to find three main buckling modes. It was found that delamination position and lay-up can affect the buckling mode and also the critical buckling load. By approaching the delamination position to the outer surface of the specimen the buckling load decreases. The buckling process of hybrid and non-hybrid composite beams was also simulated by finite element software ANSYS and the critical buckling loads were verified with the relevant experimental results.
\end{abstract}

\section{Introduction}

Fibre-reinforced polymer (FRP) composite materials are widely used because of their high strengthto-weight and stiffness-to-weight ratios as compared with many traditional materials [1,2]. Delamination is one of the most serious failure modes in laminated composite materials. It can occur in several ways during manufacturing process, maintenance and impacts of foreign objects $[2,3]$. Laminated composite materials containing one or more delamination can buckle at a lower level of compressive load than laminated composites without delamination, and this level depends on the size, position and shape of the delamination [4].

Buckling and postbuckling behaviour in delaminated composite structures have been studied to investigate the buckling resistance loads $[5,6,7,8,9]$. Most of these previous works are about buckling response of non-hybrid laminated composite structures. Hybrid laminated composites are an effective method to improve the mechanical properties of laminated composite structures under various loading conditions.

In the present study, the effect of delamination position on the critical buckling load of non-hybrid and hybrid composite laminates of CFRP and GFRP with single delamination position is studied. The laminate designs of $\left[\mathrm{G}_{90}\right]_{6},\left[\mathrm{C}_{90}\right]_{8},\left[\mathrm{C}_{0} / \mathrm{G}_{0}\right]_{4}$ and $\left[\mathrm{C}_{90} / \mathrm{G}_{90}\right]_{4}$ were chosen to compare the buckling resistance of hybrid and non-hybrid composite beams. The delaminated composite beams were manufactured and tested to find the critical buckling load. The buckling behaviour of hybrid and non-hybrid composite beams was also simulated using ANSYS software to compare numerical and experimental buckling modes and the numerical critical buckling loads were verified with relevant experimental results. 


\section{Experimental details}

\subsection{Manufacturing}

The delaminated composite beams of $\left[\mathrm{G}_{90}\right]_{6},\left[\mathrm{C}_{90}\right]_{8},\left[\mathrm{C}_{0} / \mathrm{G}_{0}\right]_{4}$ and $\left[\mathrm{C}_{90} / \mathrm{G}_{90}\right]_{4}$ were manufactured from the unidirectional GFRP and CFRP composites. The thickness of all laminated beams was 2 $\mathrm{mm}$. Three defect positions of $H / t=0.5,0.25$ and 0.125 were chosen and Teflon film of $13 \mu \mathrm{m}$ was placed at these particular positions to model the delaminated composite beams. The geometry of a composite beam with a single delamination is shown in Fig. 1.

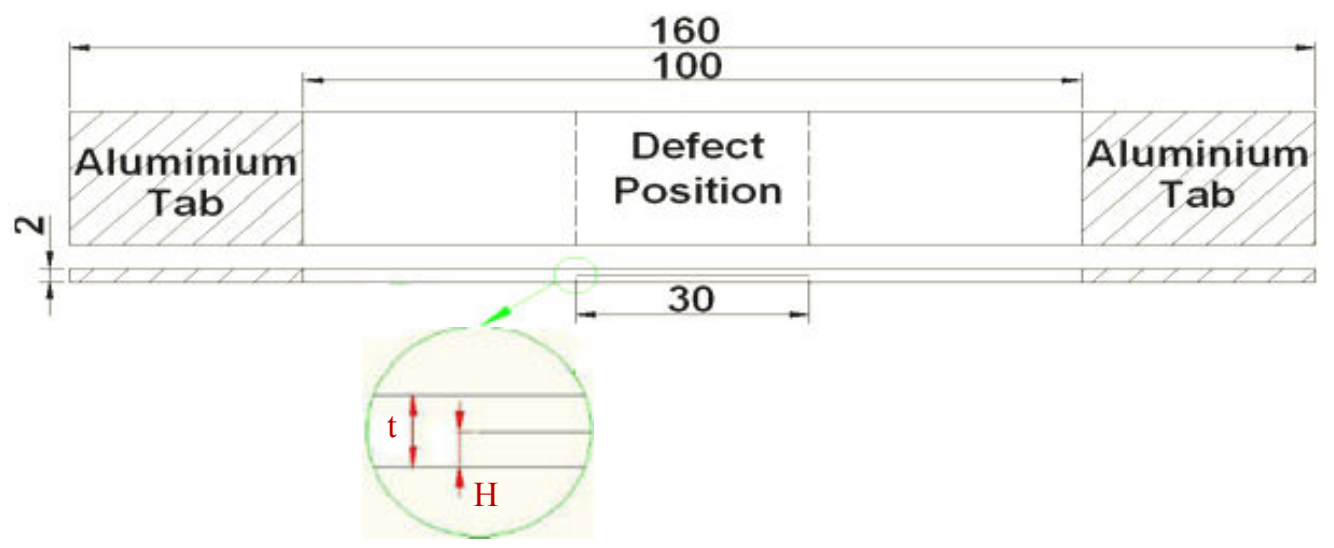

Figure 1. Geometry of delaminated composite plate with various delamination positions.

\subsection{Mechanical properties}

The mechanical characteristics of carbon/epoxy and glass/epoxy were obtained in accordance with the relevant standards [10-13]. These tests were tensile, shear, fibre volume fraction and coefficient of friction. All specimens were manufactured from carbon fibre reinforced plastic (CFRP) and glass fibre reinforced plastic (GFRP) materials of density $1.8 \mathrm{~g} / \mathrm{cm}^{3}$ and $1.6 \mathrm{~g} / \mathrm{cm}^{3}$ with epoxy resin. A summary of the findings for tensile, shear and fibre volume fraction are summarised in Table 1.

Table 1. Material properties of the unidirectional CFRP and GFRP composites.

CFRP

\begin{tabular}{cccccccc}
\hline $\begin{array}{c}E_{1} \\
(\mathrm{GPa})\end{array}$ & $\begin{array}{c}E_{2} \\
(\mathrm{GPa})\end{array}$ & $\begin{array}{c}G_{12} \\
(\mathrm{GPa})\end{array}$ & $v_{12}$ & $\begin{array}{c}\sigma_{u} 0^{\circ} \\
\mathrm{MPa}\end{array}$ & $\begin{array}{c}\sigma_{u} 90^{\circ} \\
\mathrm{MPa}\end{array}$ & $\begin{array}{c}\tau_{\mathrm{s}} \\
\mathrm{MPa}\end{array}$ & $\begin{array}{c}V_{f} \\
(\%)\end{array}$ \\
\hline $138 \pm 12$ & $10.5 \pm 1$ & $6.3 \pm 0.4$ & 0.1 & $330 \pm 14$ & $32 \pm 4$ & $147 \pm 14$ & 42 \\
\hline
\end{tabular}

GFRP

\begin{tabular}{cccccccc}
\hline$E_{1}$ & $E_{2}$ & $G_{12}$ & $v_{12}$ & $\begin{array}{c}\sigma_{u} 0^{\circ} \\
\mathrm{MPa}\end{array}$ & $\begin{array}{c}\sigma_{u} 90^{\circ} \\
\mathrm{MPa}\end{array}$ & $\begin{array}{c}\tau_{\mathrm{s}} \\
\mathrm{MPa}\end{array}$ & $\begin{array}{c}V_{f} \\
(\%)\end{array}$ \\
\hline $35.1 \pm 4$ & $9.6 \pm 1$ & $4 \pm 0.5$ & 0.32 & $807 \pm 10$ & $21.3 \pm 2$ & $97.9 \pm 4$ & 40.3 \\
\hline
\end{tabular}




\subsection{Buckling test}

Each specimen was tested at the rate of $0.2 \mathrm{~mm} / \mathrm{min}$ using a Universal Testing Machine with $50 \mathrm{kN}$ load cell. For each test configuration three specimens were tested. The force-displacement diagrams were recorded automatically for each test (see Fig. 2).

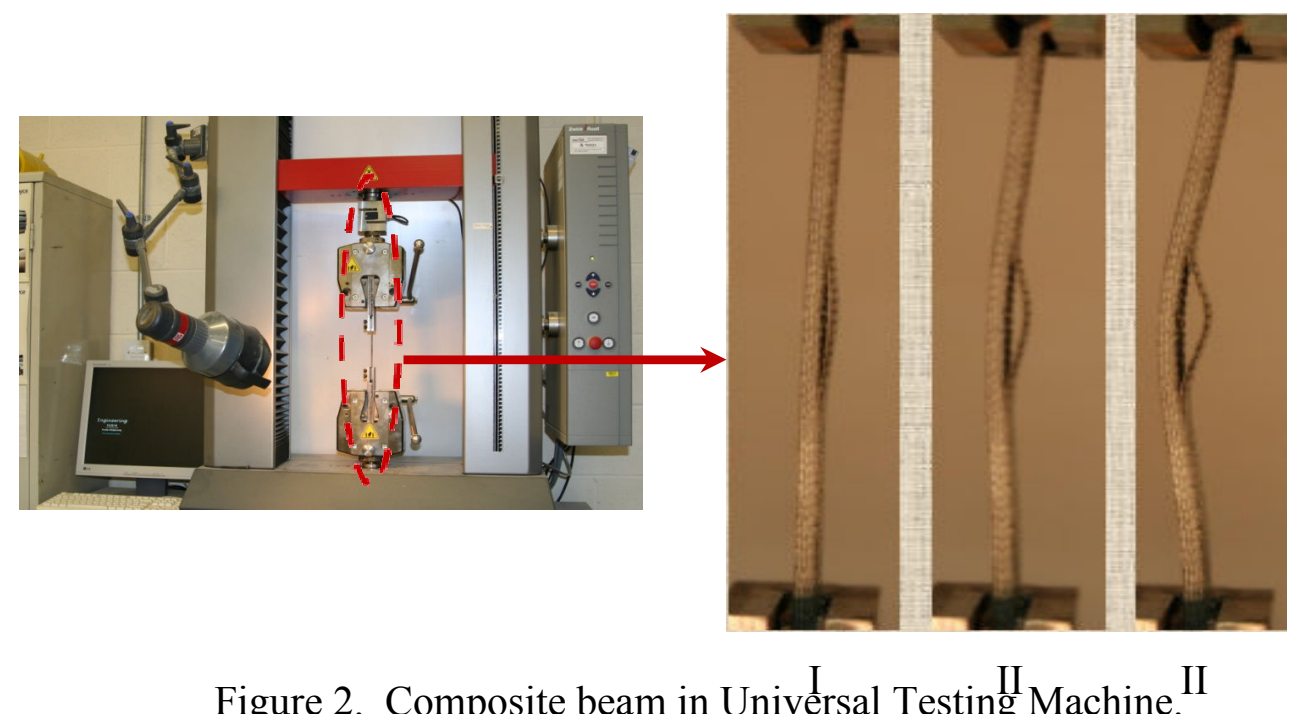

Figure 2. Composite beam in Universal Testing Machine.

All experimental force-displacement results for various laminate designs at different delamination positions are presented in Fig 3.
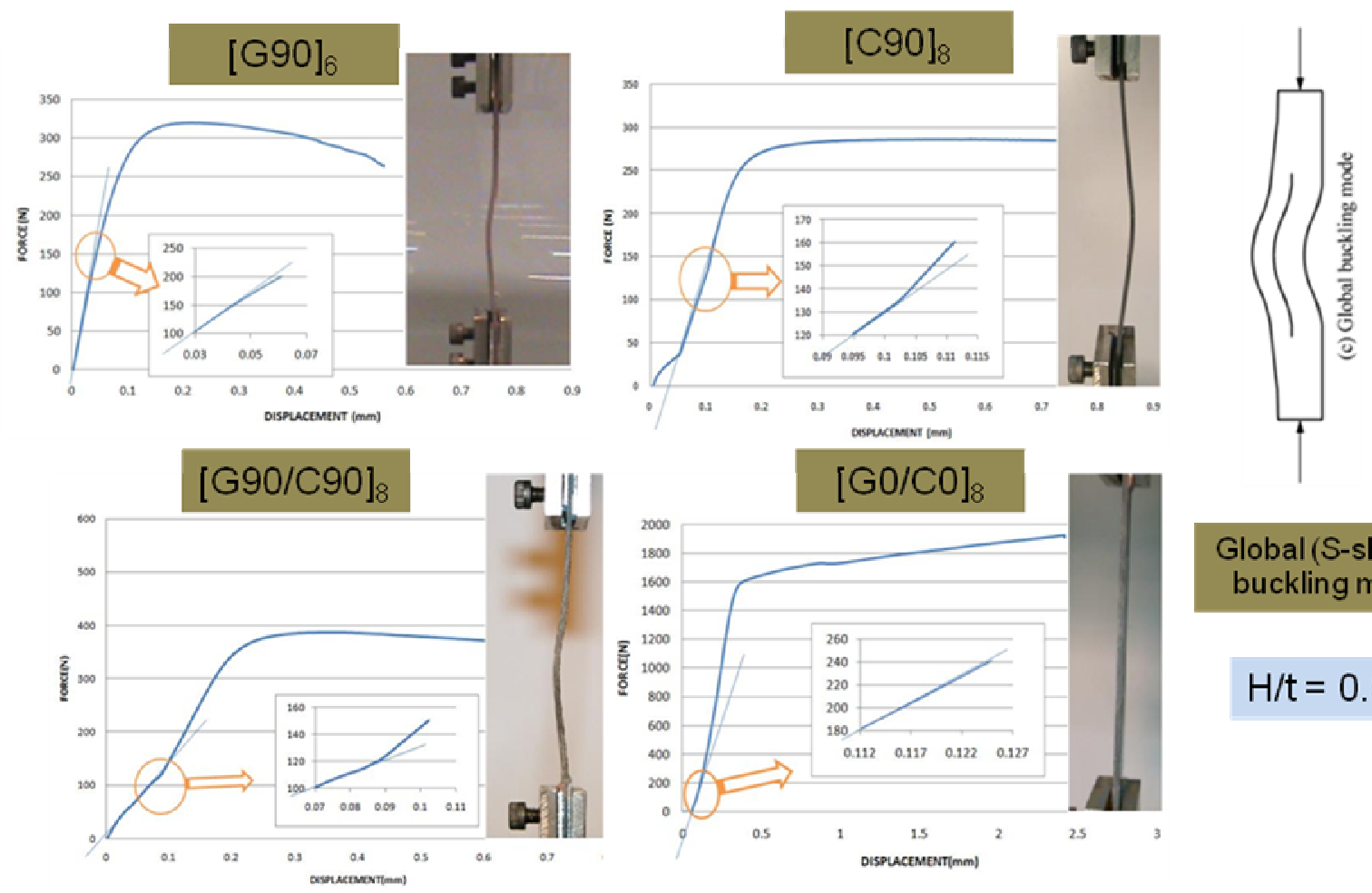

\section{Global(S-shape) \\ buckling mode}

$H / t=0.5$

Figure. 3.a Experimental force-displacement results for global buckling mode at delamination position of $\mathrm{H} / \mathrm{t}=0.5$. 


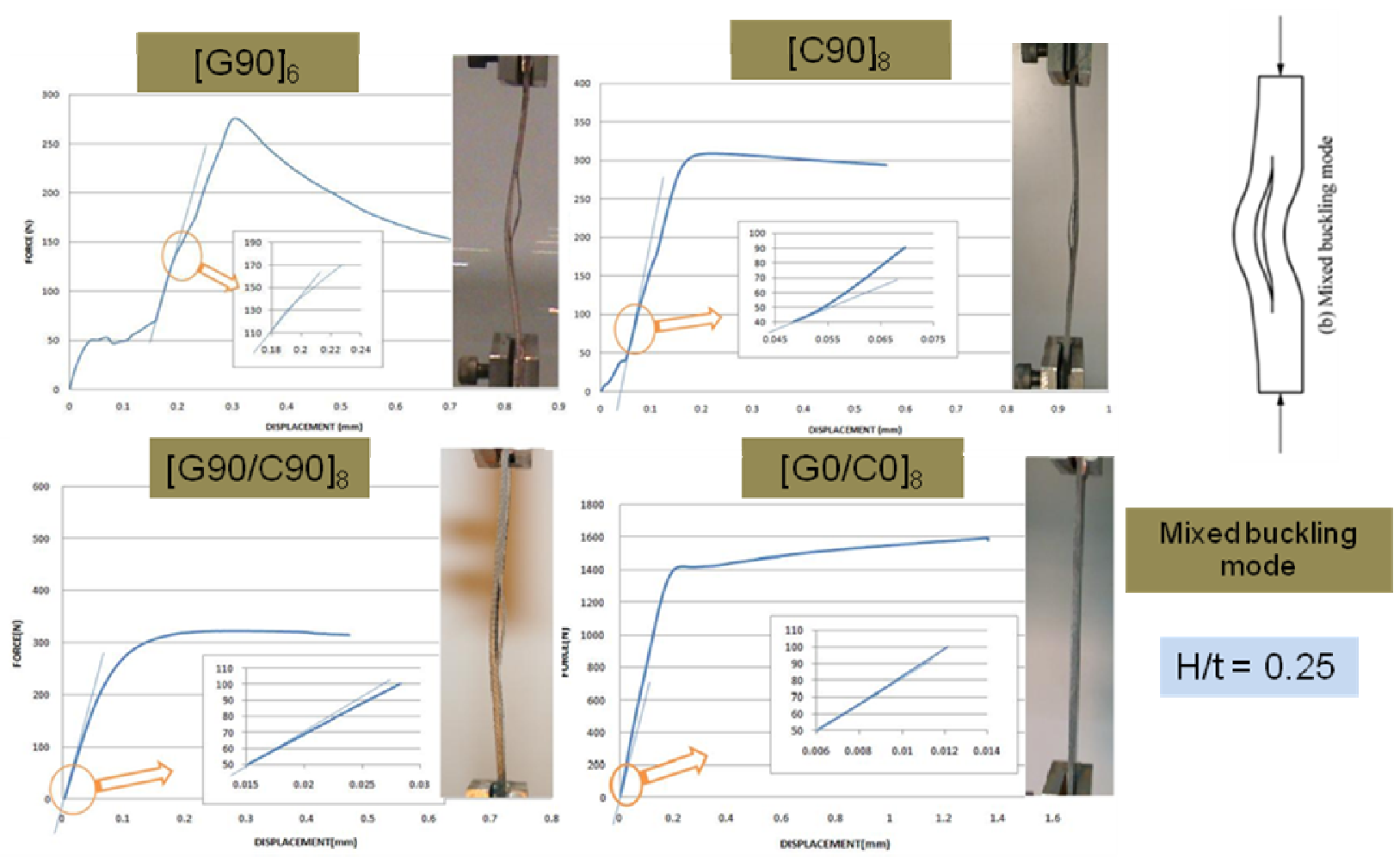

Figure. 3.b Experimental force-displacement results for mixed buckling mode at delamination position of $\mathrm{H} / \mathrm{t}=0.25$.
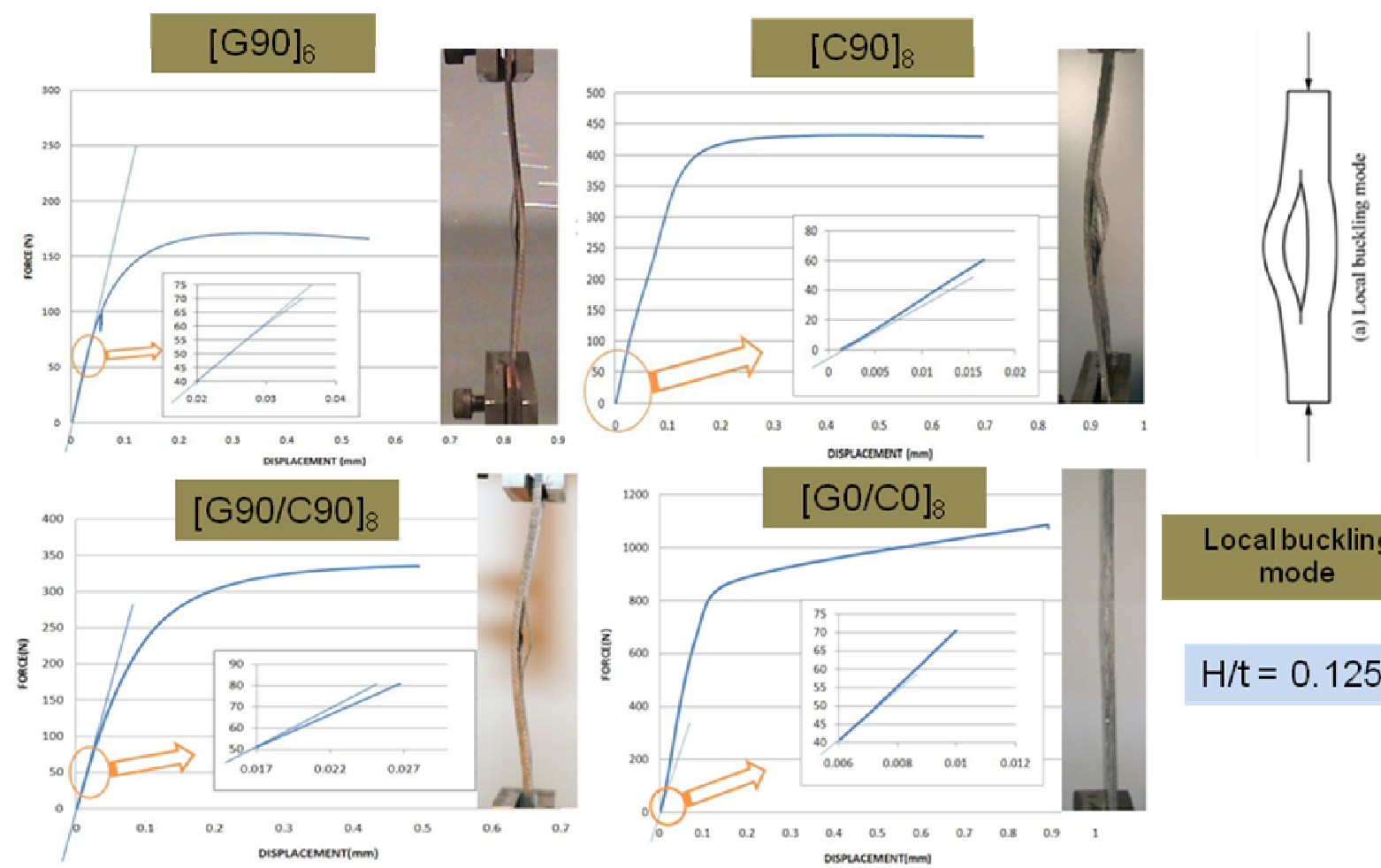

Local buckling mode

$\mathrm{H} / \mathrm{t}=0.125$

Figure. 3.c Experimental force-displacement results for local buckling mode at delamination position of $\mathrm{H} / \mathrm{t}=0.125$. 


\section{Numerical study}

In the present work, Eigen-buckling analysis was performed to simulate the buckling behaviour of delaminated composite beams. The element type of SOLID46 layered element with six degree of freedom was chosen to create mesh for laminated composite beam. To simulate the boundary conditions all degrees of freedom at one end of composite beam were set equal to zero.

The delaminated composite beam was designed with 6 volumes to model the single delamination (see Fig. 4). To simulate the delamination area at the first interface, top and bottom area of volumes were not glued in the interfacial areas. Thus, double nodes occur at the same coordinates of the interfacial areas. During the buckling simulation the double nodes separate from one another. In this case, other areas which were not glued represent delamination in the laminated composite beam.

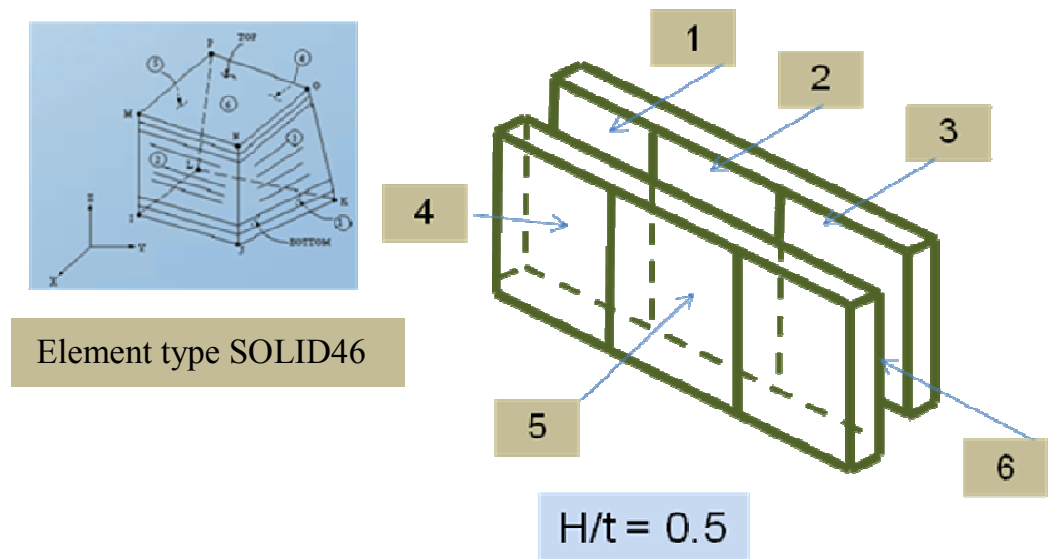

Figure. 4. Numerical modeling of delaminated composite beam at defect position of $\mathrm{H} / \mathrm{t}=0.5$.

The numerical results and their comparison with experimental results are presented in Fig. 5.

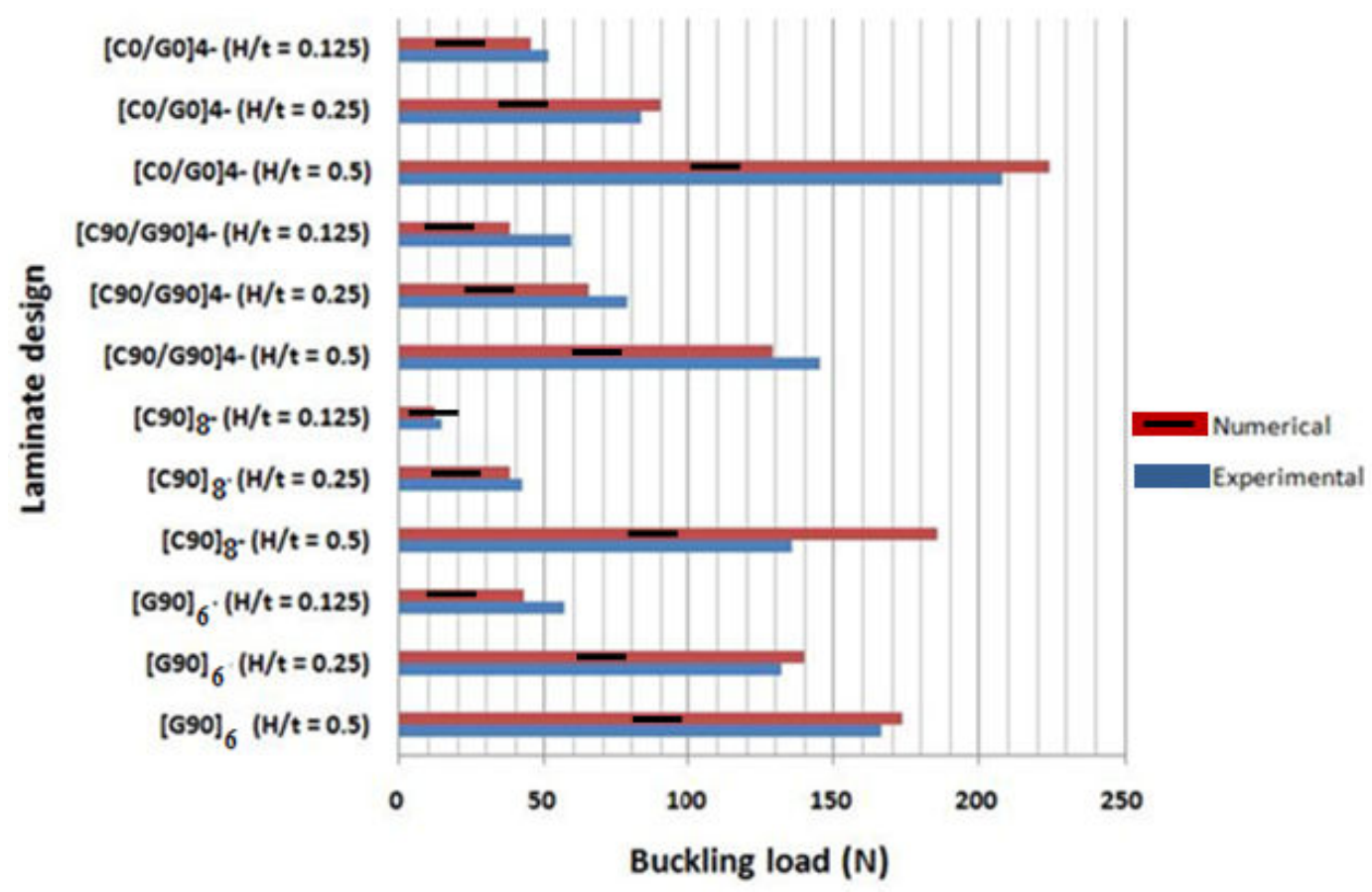

Figure 5. Comparison of experimental and numerical critical buckling loads. 


\section{Results and discussion}

The experimental and numerical critical buckling loads of various lay-ups are presented in Figs. 6 and 7. The experimental results are the average of three tests for each specimen. The critical buckling load at different defect positions were compared together and good agreement were found between experimental and FE results. It is noteworthy that this type of simulation is suitable for linear buckling behaviour of composite beam. However in this study post-buckling and delamination failure are not considered. Our results indicate that hybrid composite beams are able to show more resistance against buckling load in comparison with non-hybrid composite beams. By decreasing the $\mathrm{H} / \mathrm{t}$ ratio the critical buckling resistance load decreases for all non-hybrid and hybrid laminated composite beams.
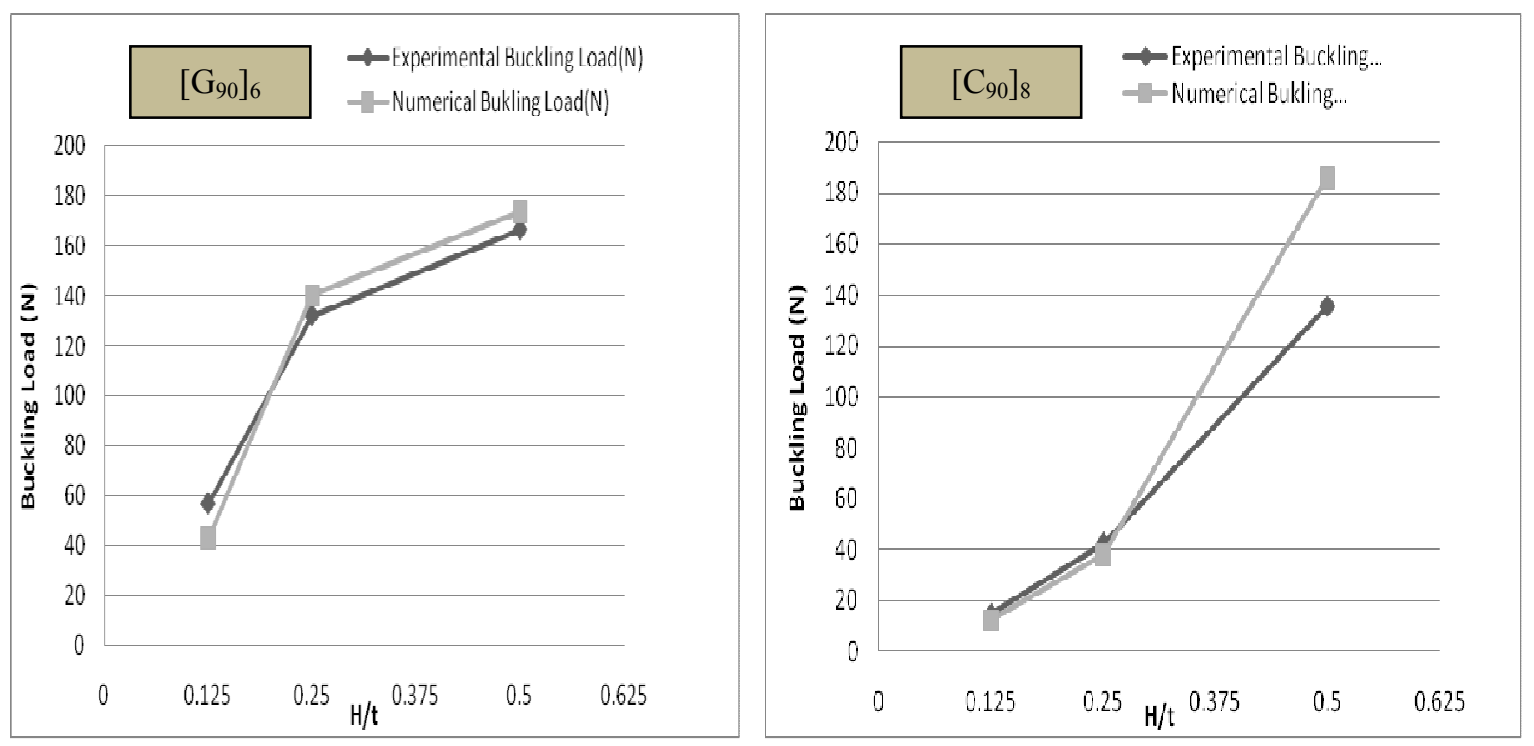

Figure 6. Comparison of buckling load in three defect positions for non-hybrid composite beams with laminate designs of $\left[\mathrm{G}_{90}\right]_{6}$ and $\left[\mathrm{C}_{90}\right]_{8}$.
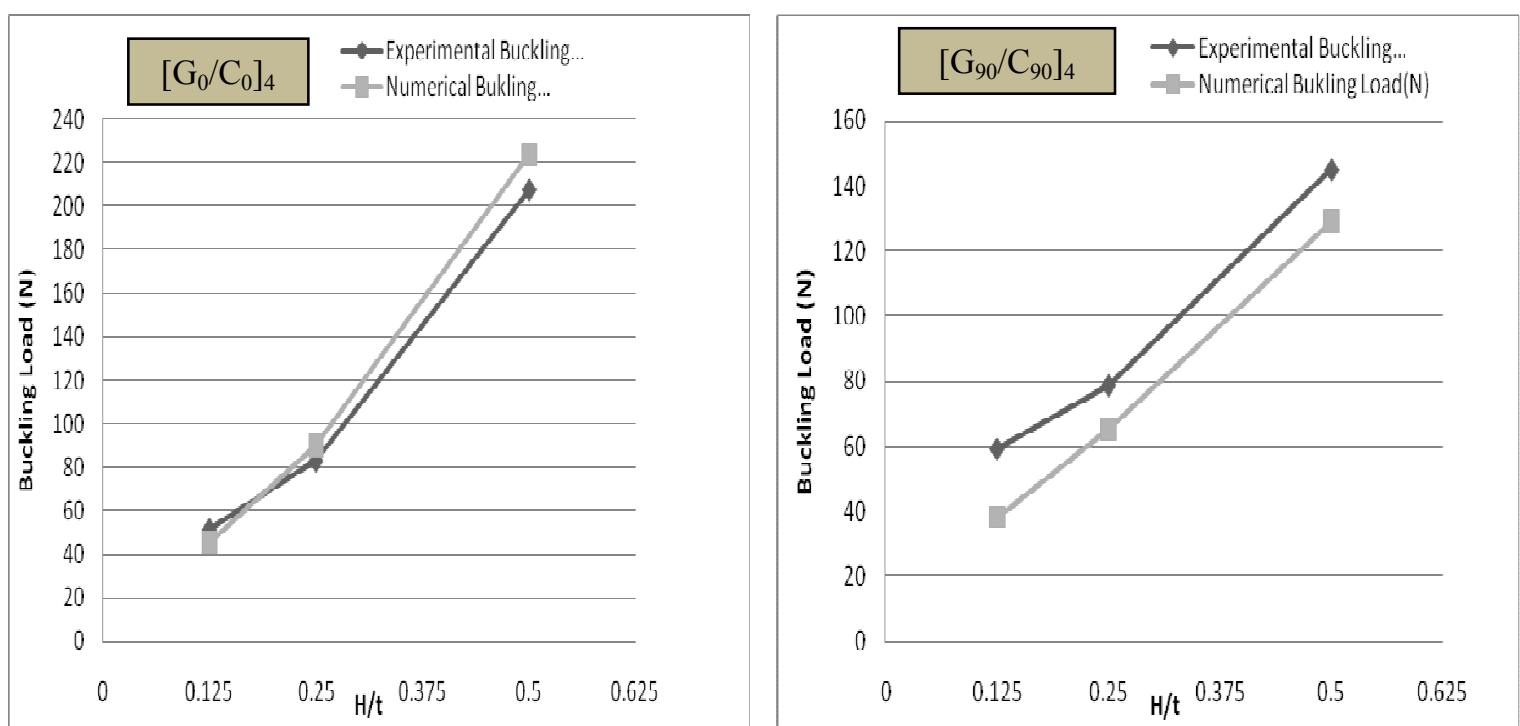

Figure 7. Comparison of buckling load in three defect positions for hybrid composite beams with laminate designs of $\left[\mathrm{G}_{90} / \mathrm{C}_{90}\right]_{4}$ and $\left[\mathrm{G}_{0} / \mathrm{C}_{0}\right]_{4}$. 
The buckling modes of global, local and mixed are compared for three defect positions in laminated composite beams. Good agreement was found between numerical and experimental buckling modes in all delaminated composite beams. This simulation method could be a new method to predict the critical buckling load of delaminated composite materials. The comparison between numerical and experimental results for three laminate designs of $\left[\mathrm{G}_{90}\right]_{6},\left[\mathrm{C}_{90}\right]_{8},\left[\mathrm{C}_{90} / \mathrm{G}_{90}\right]_{4}$ indicates that global buckling mode occurs for the defect position of $H / t=0.5$, as well as mixed buckling mode for defect position of $H / t=0.25$, and local buckling mode for defect position of $H / t=0.125$ (see Fig. 8).

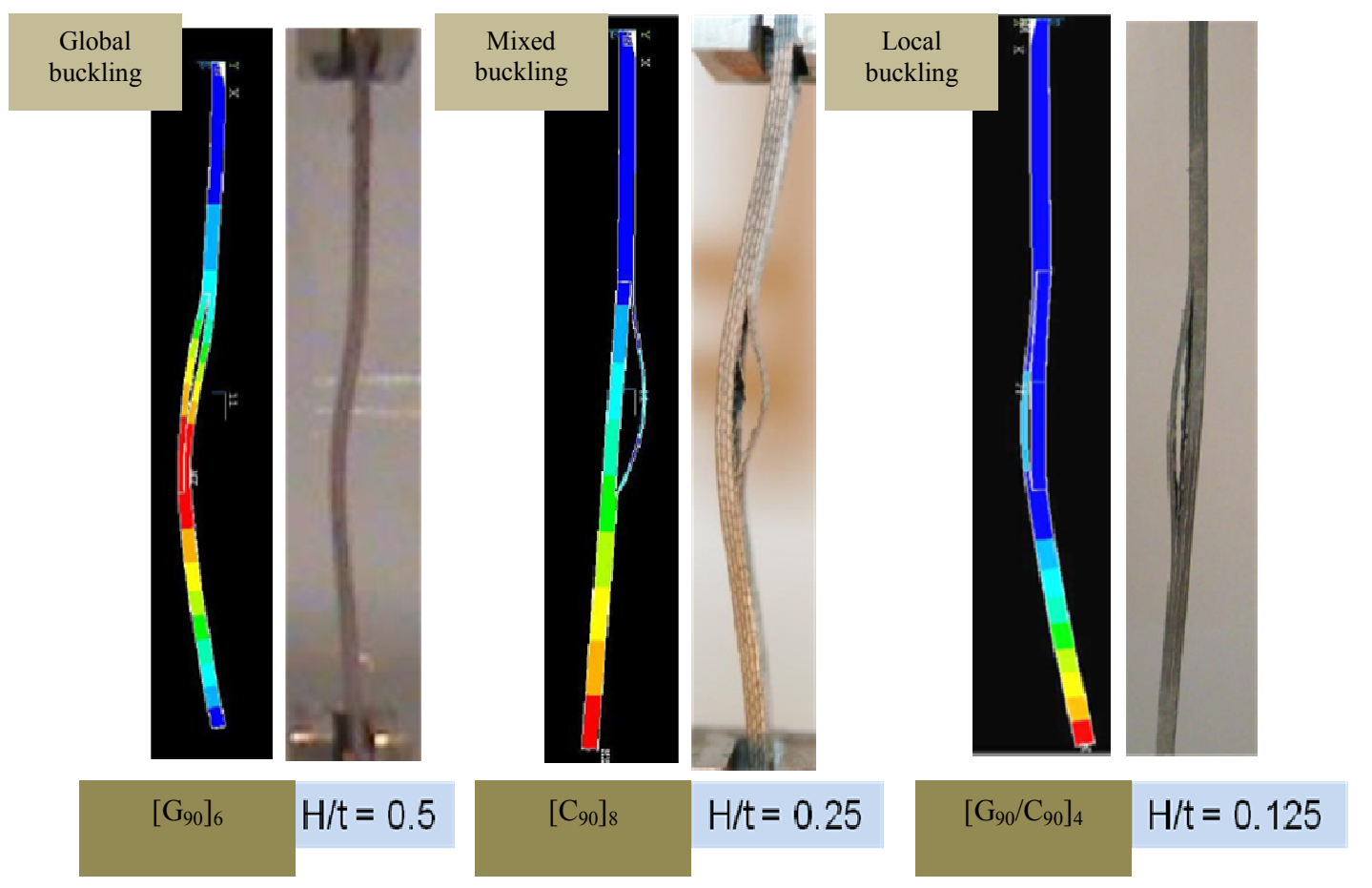

Figure 8 . Three distinct buckling modes in delaminated composite beams.

\section{References}

[1] H. Ghasemnejad, H. Hadavinia, and A. Aboutorabi, in: Effect of Delamination Failure in Crashworthiness Analysis of Hybrid Composite Box Structures, Materials and Design, 31(3),pp.1105-1116,(2010).

[2] H. Ghasemnejad, BRK Blackman, H Hadavinia \& B Sudall, in: Experimental studies on fracture characterisation and energy absorption of GFRP composite box structure, Composite Structures, 88(2),pp.253-261,(2008).

[3] Z. Aslan, and M. Şahin, in: Buckling behaviour and compressive failure of composite laminates containing multiple large delaminations. Composite Structures, 89(3), pp. 382-390 (2009). 
[4] M. Zor, F. Sen, ME. Toygar, in: An investigation of square delamination effects on the buckling behavior of laminated composite plates with a square hole by using threedimensional FEM analysis. J Reinf Plast Compos, 24(11),pp.19-30 (2005).

[5] YC. Wee, CG. Boay, in: Analytical and numerical studies on the buckling of delaminated composite beams. Composite Structures, 80(2), pp.307-319 (2007).

[6] F. Cappello, D. Tumino, in: Numerical analysis of composite plates with multiple delaminations subjected to uniaxial buckling load. Composites Science and Technology, 66,pp. 264-272,(2006)

[7] G. Li, SS. Pang, Y. Zhao, SI. Ibekwe, in: Local buckling analysis of composite laminate with large delaminations induced by low velocity impact. Polymer Composites, 20(5),pp. 634-642,(2009).

[8] S. Moradi, F. Taheri, in: Delamination buckling analysis of general laminated composite beams by differential quadrature method. Composites Part B: Engineering, 30(5),pp.503511,(2009).

[9] WM. Kyoung, CG. Kim, CS. Hong, SM. Jun, in: Modelling of composite laminates with multiple delaminations under compressive loading. Journal of Composite Materials, 10(32),pp.951-968,(2009)

[10] BS EN ISO 2747, Glass Fibre Reinforced Plastics-Tensile Test, British Standard Institute, London, 1998.

[11] BS EN ISO 14129, Fibre Reinforced Plastics Composite-Determination of the In-plane Shear Stress/Shear Strain Response, Including the In-plane Shear Modulus and Strength by the \pm 45 Tension Test Method, British Standard Institute, London, 1998 .

[12] ASTM D 3171-99, Standard test method for constituent content of composite materials. Annual book of ASTM standards, West Conshohocken, PA, 2002.

[13] BS EN ISO 15024:2001, Fibre-reinforced plastic composites. Determination of mode I interlaminar fracture toughness, $G_{I C}$, for unidirectional reinforced materials. BSI, 2002. 